\title{
How Do We Improve the Impact of lodine Deficiency Disorders Prevention in Europe and Beyond?
}

\author{
Henry Völzke ${ }^{a}$ Iris Erlund ${ }^{b}$ Alicja Hubalewska-Dydejczyk ${ }^{c}$ Till Ittermann ${ }^{a}$ \\ Robin P. Peeters ${ }^{d} \quad$ Margaret Rayman $^{\mathrm{e}} \quad$ Monika Buchberger $^{f} \quad$ Uwe Siebert $^{f}$ \\ Betina H. Thuesen ${ }^{g}$ Michael B. Zimmermann ${ }^{\text {h }}$ Stefan Grünert ${ }^{\mathrm{i}}$ \\ John H. Lazarus ${ }^{j}$ on behalf of the EUthyroid Consortium \\ ${ }^{a}$ Institute for Community Medicine, University Medicine Greifswald, Greifswald, Germany; ${ }^{b}$ Department of Public \\ Health Solutions, National Institute for Health and Welfare (THL), Helsinki, Finland; ' $D e p a r t m e n t$ of Endocrinology, \\ Jagiellonian University Medical College, Krakow, Poland; ${ }^{d}$ Department of Internal Medicine, Rotterdam Thyroid \\ Centre, Erasmus Medical Centre, Rotterdam, The Netherlands; e University of Surrey, Surrey, UK; fDepartment of \\ Public Health and Health Technology Assessment, UMIT, University for Health Science, Medical Informatics and

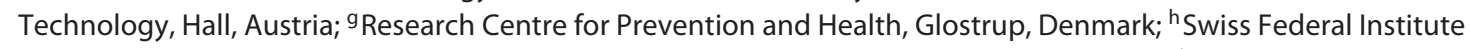 \\ of Technology, Zürich Department of Health Sciences and Technology, Zürich, Switzerland; 'Biolution GmbH, \\ Vienna, Austria; 'ं Institute of Molecular Medicine, Cardiff University, Cardiff, UK
}

\section{Keywords}

lodine · Prevention · Epidemiology · Outcomes research

\begin{abstract}
Background: lodine deficiency disorders (IDD) represent a global health threat to individuals and societies. IDD prevention programmes have been introduced in many parts of the world. However, challenges remain, particularly in Europe due to fragmentation and diversity of approaches that are not harmonized. Objectives: This review is dedicated to the public-health impact of IDD prevention programmes. It sums up experiences collected by the EUthyroid consortium so far and provides information on stakeholders that should be involved in actions directed to improve the impact of IDD
\end{abstract}

\section{KARGER}

E-Mail karger@karger.com www.karger.com/etj prevention. Methods: A joint European database for combining registry-based outcome and monitoring data as well as tools for harmonizing study methods were established. Methods for analyzing thyroglobulin from a dried blood spot are available for assessing the iodine status in the general population and at-risk groups. Mother-child cohorts are used for in-depth analysis of the potential impact of mildto-moderate iodine deficiency on the neurocognitive development of the offspring. A decision-analytic model has been developed to evaluate the long-term effectiveness and cost effectiveness of IDD prevention programmes. $\boldsymbol{R} \boldsymbol{e}$ sults: EUthyroid has produced tools and infrastructure to improve the quality of IDD monitoring and follows a dissemination strategy targeting policymakers and the general public. There are tight connections to major stakeholders (c) 2018 European Thyroid Association

Published by S. Karger AG, Basel 
in the field of IDD monitoring and prevention. Conclusions: EUthyroid has taken steps towards achieving a euthyroid Europe. Our challenge is to inspire a greater sense of urgency in both policymakers and the wider public to address this remediable deficit caused by IDD.

(C) 2018 European Thyroid Association Published by S. Karger AG, Basel

\section{Background}

Iodine deficiency disorders (IDD) represent a global health threat to individuals and societies. According to the World Health Organization, iodine deficiency is the single most important, preventable cause of brain damage worldwide [1]. Iodine deficiency during pregnancy and breast feeding is widespread in Europe and adversely affects the development of the child [1]. Adults living in iodine-deficient regions carry a high risk of goiter, thyroid nodules and hyperthyroidism. Subclinical hyperthyroidism, as a common and frequently undiagnosed IDD $[2,3]$, is tightly associated with an increased risk of mortality and coronary heart disease [4].

Thus, effects of iodine deficiency impose tremendous, preventable resource costs on the health-care systems of affected regions. Iodine deficiency can easily be prevented by iodine fortification and was pioneered in Switzerland in 1922 [5]. Since then, IDD prevention programmes have been introduced in many parts of the world by fortifying table salt, staple foods and livestock feed. However, challenges remain, particularly in Europe, due to fragmentation and diversity of approaches. To the extent that regular programmes exist at all, iodine fortification may be based on the voluntary or the mandatory principle, different carriers are used (e.g., potassium iodide or iodate), different foods may be iodized (e.g., bread, dairy products) and target concentrations for salt iodization vary. Similarly, monitoring and evaluation of IDD prevention programmes across nations is either absent or not systematic. Moreover, the cost-effectiveness of IDD prevention has rarely been explored, probably because it is widely assumed that due to the low cost of salt fortification, such programmes provide value for money.

This review is dedicated to the public-health impact of IDD prevention programmes and is intended to provide background information of the Krakow Declaration of Iodine, which is published in this issue of the European Thyroid Journal [6]. The review sums up experiences collected by the EUthyroid consortium so far and provides information on stakeholders that should be involved in actions directed to improve IDD prevention.

This heterogeneity in national regulations poses challenges to large European food companies and has resulted in a decreasing proportion of iodine-fortified food.

\section{EUthyroid: To Improve the Level of Scientific Evidence}

\section{Objectives}

In the era of fake news and conspiracy theories, sound scientific evidence remains a pivotal precondition for political decisions. EUthyroid, a pan-European consortium, was formed in close cooperation with the Iodine Global Network (IGN). EUthyroid is working towards the following specific objectives with the aim of ending IDD in Europe and beyond:

1. Collation of national registry data to analyze associations between iodine status and disease outcomes;

2. Harmonization of national iodine studies to produce a valid European map of iodine status;

3. Capacity building for harmonized IDD prevention and monitoring, including assessment of thyroglobulin (Tg) as an innovative and cost-effective biomarker of iodine status in individuals and populations;

4. Evaluation of Tg in pregnant women as a biomarker for iodine status and the effect of maternal iodine status on neurocognitive function in children;

5. Proof of long-term cost-effectiveness of IDD prevention and monitoring programmes in European regions with mild-to-moderate iodine deficiency;

6. Support for harmonized IDD prevention and monitoring in European countries through dissemination of EUthyroid outcomes.

\section{Results}

\section{Registry-Based Outcomes}

While a large number of studies that monitor the iodine status in populations exist, there is almost no outcome research that provides evidence of the effectiveness of IDD prevention programmes in terms of declining prevalence and incidence of IDDs and related therapies [7]. A joint European database for combining national/ regional registry-based outcome data related to iodine status has been established.

Experience: The extreme heterogeneity of registry data across European countries is a great challenge for outcome research. In many countries, access to registry data is hindered by so-called data protection. Outcome data in a single 
country is sometimes collected by different institutions such as health insurance companies and various associations of health-care providers. In federally structured countries, nationwide data is sometimes unavailable. Across European countries, there are no general recommendations, guidelines, or standards on how to collect specific data, and this trend hampers data comparability between countries. However, registry data can be very useful for comparisons across, for example, the Scandinavian countries where nationwide registry data is collected for administrative purpose and where the health care systems are similar.

Conclusion: Policymakers have to be made aware of their public health-related responsibilities and the fact that the evaluation of IDD prevention programmes in their countries is obligatory. European and national authorities have to ensure the accessibility of data for health research. Access procedures, database structure and regulatory frameworks for use of health-care data should be harmonized within and across European countries.

Harmonization of National IDD Monitoring Studies

EUthyroid has improved the harmonization of national and regional IDD monitoring studies by standardizing them, collecting national and regional IDD data to establish a joint European database with information on the prevalence of thyroid-related biomarkers. Online tools and infrastructures enabling a continuous harmonization of data collection and monitoring have been established. One of the key features is the gold-standard EUthyroid laboratory. It has detected large inter-laboratory differences in measurement of urinary iodine concentrations between national laboratories, clearly emphasizing the need for more work to improve the validity of iodine analysis for thyroid epidemiology [8] (Fig. 1, 2).

The same challenges were noted in the collection of interview and ultrasound data. Standardized questionnaires to assess the socioeconomic status in different languages are available (http://euthyroid.eu/questionnaires-page/) as well as training and certification tools for laboratory staff and sonographers (http://euthyroid.eu/training/).

The joint database of harmonized regional and national IDD monitoring studies has been the basis for the mapping the iodine status and thyroid disorders (Fig. 3). The EUthyroid map is available at http://euthyroid.eu/map/.

Experience: The quality of monitoring studies is heterogeneous. Common limitations include non-representative study populations and inadequate standardization of interviews, ultrasound examinations and laboratory procedures, resulting in low validity of some study results and hampered comparability between studies from different countries.

Public-Health Impact of Thyroid Research

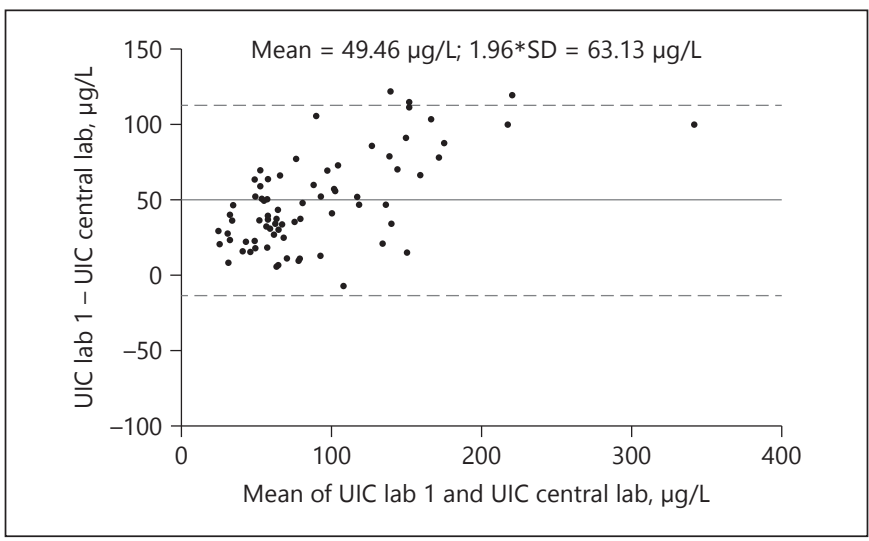

Fig. 1. Comparison of urinary iodine concentration (UIC) levels $(\mu \mathrm{g} / \mathrm{L})$ between one national laboratory and the EUthyroid laboratory. As illustrated by Bland and Altman plot, the national laboratory measures on average $49.46 \mu \mathrm{g} / \mathrm{L}$ higher values than the goldstandard laboratory in the same urine samples. The differences are even higher in the upper measurement range.

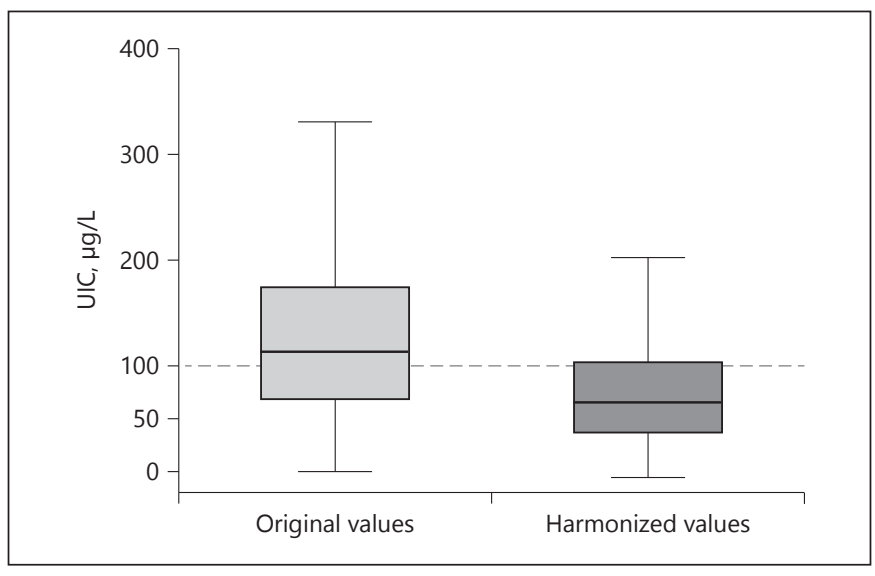

Fig. 2. Example of urinary iodine excretion (UIE) levels before (left boxplot) and after correction for the gold-standard measurements (right boxplot). The status of the investigated population changed from iodine sufficiency to moderate iodine deficiency. UIC, urinary iodine concentration.

Conclusion: Policymakers and government officials must be made aware that they are responsible for the monitoring of IDD prevention programmes in their countries. Researchers do not have to ask for monitoring studies to be carried out; politicians should ask researchers to carry out appropriate monitoring that achieves the best possible population representativeness and validity of study results. On the European (and global) level, intensive efforts are required to establish and extend tools and infrastructure for standardization and quality assurance in monitoring studies. 
Fig. 3. Region of the EUthyroid map illustrating the iodine status of populations measured as urinary iodine concentration. The map not only provides information on countries as a whole, but also on regions and communities, where iodine monitoring studies have been performed.

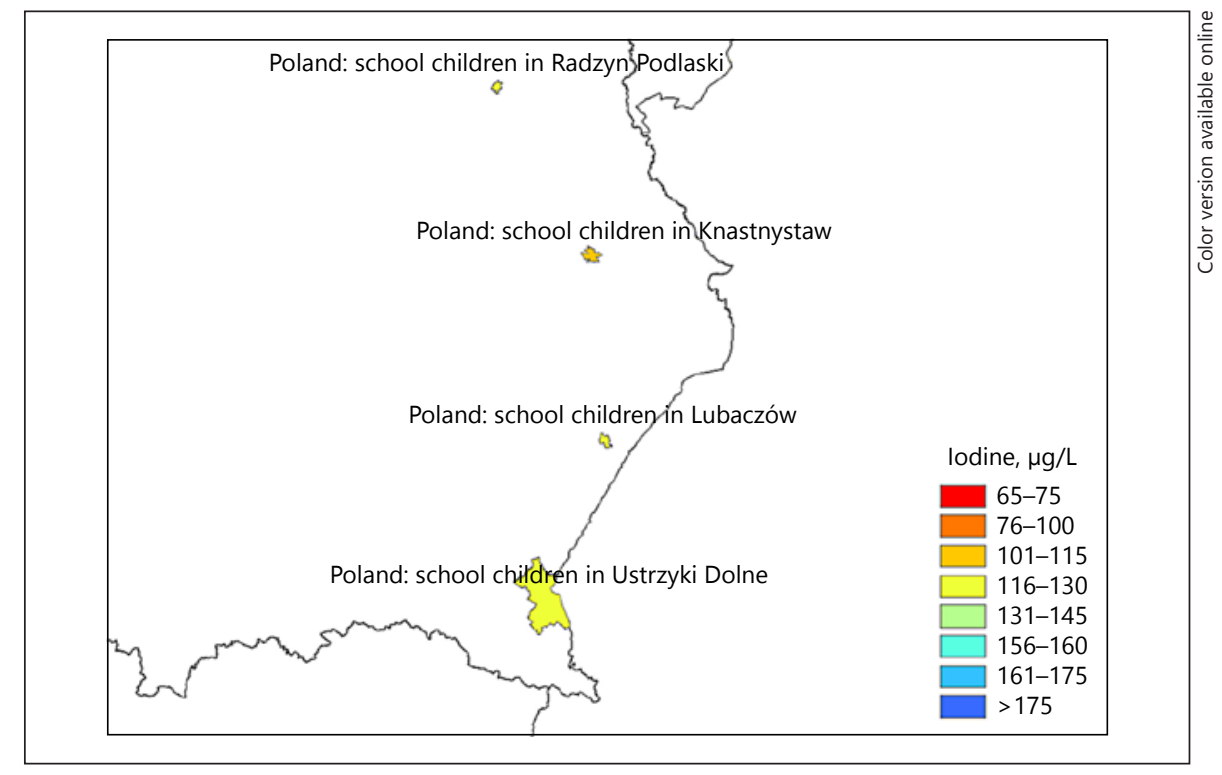

Thyroglobulin

Tg is a thyroid-specific protein and a storage and synthesis site for thyroid hormones. During iodine deficiency or excess, the increase in the thyroid activity leads to an increase in the blood Tg concentration [9]. Tg can be measured in dried blood spots (DBS), which can simplify collection, storage and transport in field studies. DBS-Tg could also be a sensitive functional biomarker to assess iodine status in pregnant women and women of reproductive age [4]. However, there is less data on Tg concentrations in women of varying iodine intake in Europe.

Experience: Although collection and analysis of DBS $\mathrm{Tg}$ from women across Europe is ongoing, preliminary data suggests that day-to-day variation in DBS-Tg is modest and that DBS Tg may be a good functional indicator of iodine status in European pregnant women [10].

Conclusion: Although DBS Tg is a promising biomarker of iodine status in pregnant women, there may be additional environmental and genetic factors that influence $\mathrm{Tg}$ concentrations, and these need to be further investigated before $\mathrm{Tg}$ can be recommended for routine use in monitoring the iodine status.

Maternal Iodine Status during Pregnancy and

Neuropsychological Development of the Offspring

Although the negative consequences of severe iodine deficiency for offspring neurocognitive development are beyond doubt [11], the effects of mild-to-moderate iodine deficiency on cognition are relatively unexplored. EUthyroid overcomes this knowledge gap by providing new data on maternal iodine status in relation to neuroments and harmonizing and integrating data from 3 large European cohorts of different iodine status.

Experience: More evidence is needed that even mildto-moderate iodine deficiency during pregnancy affects offspring neurocognitive development, but given the long-term follow-up needed to obtain valid results, the potential study base is sparse. The collaboration between 3 major European prospective mother-child cohorts in the EUthyroid consortium of differing iodine status (i.e., ALSPAC [12], moderately iodine deficient; INMA [13], mildly iodine deficient; Generation R [14], iodine sufficient) allows an individual participant-based meta-analysis to relate maternal iodine status in pregnancy to offspring neurocognitive function. Primary neurocognitive outcome will be child IQ (5-10 years of age) and secondary outcomes will include neuropsychological diseases.

Conclusion: When there is more evidence from observational studies that mild-to-moderate iodine deficiency during pregnancy affects the neurocognitive function of the offspring, and which women are particularly at risk, subsequent clinical trials are needed to demonstrate beneficial effects of iodine supplementation.

Health Economics, Health Technology Assessment and Health Policy

Due to a variety of IDD prevention programmes and associated complex and uncertain consequences, it is essential for decision makers systematically to evaluate benefits, potential harms and cost-effectiveness of prevention strategies. EUthyroid has developed a decision-analytic development, by performing additional iodine measure- 
model [15] to evaluate the long-term effectiveness and cost effectiveness of IDD prevention programmes. All relevant health conditions and events potentially caused by iodine deficiency or affected by related prevention programmes are included. The natural history of IDDs and related disorders as well as the parameters for effectiveness, quality of life and costs are derived from clinical trials, observational studies and expert surveys. Since long-term effectiveness data is rarely available in the field, the model can also be used to explore the effect of uncertainty regarding the duration of the effect of a prevention program that may suggest the need for further empirical research.

Experience: There is surprisingly low evidence of cost effectiveness of IDD prevention based on existing programmes.

Conclusion: More evidence on cost-effectiveness of IDD prevention may convince health authorities to pay more attention on the optimization of prevention programmes. Cost-effectiveness analyses must take into account the need for information campaigns, monitoring studies and evaluation analyses.

\section{Monitoring lodine Status and Evaluation of IDD Prevention}

Monitoring studies serve to inform the practicalities of iodine fortification. Changes in the political environment, food production or dietary habits may lead to unforeseeable changes in the iodine status of populations [16]. There are no specific recommendations on time intervals between monitoring studies but countries should consider regular 5-year intervals. Given the low prevalence of thyroid diseases and related treatments in young people, monitoring studies should preferably be done in school-children. Studies should be representative of the investigated region and, owing to the high intra-individual variation in iodine intake, should comprise at least 100 participants per study region [17]. The calculation of iodine intake from food-frequency questionnaires may be complicated by highly variable iodine content in foods; this may especially be the case in regions with IDD prevention programmes based on the voluntary principle [18]. The measurement of iodine from urinary samples is a well-established method [7], but should be done in certified laboratories. Alternatively or additionally, measurements of thyroglobulin in DBS can be used to define iodine status [19]. Complementary monitoring studies should be conducted in risk groups that are especially prone to IDD, including, for example, pregnant women and women of reproductive age [20].

Public-Health Impact of Thyroid Research
The primary goal of prevention measures is to reduce the burden of disorders related to iodine deficiency in societies. Monitoring cannot substitute studies for the effectiveness of IDD prevention.

The use of health-registry data is an efficient way to assess indicators of effectiveness of IDD prevention [21]. Optimal IDD prevention is reached when there is a balance between a low incidence of IDD, including hypothyroidism in newborns and goiter, thyroid nodules and hyperthyroidism in adults, on the one hand, and autoimmune thyroid disease and hypothyroidism on the other hand. Over the course of IDD prevention, registry data should demonstrate a reduction in thyroid-related therapies over time [7].

\section{Stakeholder Institutions and Organizations}

\section{EU and DG Sante}

EUthyroid recognizes that the EU is unable to provide general legislation for all states concerning recommendations for optimal iodine nutrition for the population. However, it is to be hoped that the EU will take note of the findings of EUthyroid and use these to underpin public health policy advice to individual member states. In the long run, the EU should take responsibility for health-policy recommendations to national member states to enable the harmonization of prevention programmes for all.

\section{Implications for Public Health Officers and Public \\ Health Departments}

Due to the very high prevalence of IDD in affected populations, prevention can be easily introduced and can save cost when the programme is effective. Mandatory programmes are easier to steer than programmes based on the voluntary principle. Responsible authorities must supply budgets for accompanying information campaigns to improve the awareness of the general public; this is of particular importance for voluntary programmes.

Likewise, budgets must be made available for subsequent monitoring and continuous registry studies to control the effectiveness of IDD prevention. For the latter, health registries have to be made accessible to researchers. It is the obligation of health authorities rather than the responsibility of scientists to ensure the sustainable control of IDD prevention.

\section{Implications for the European Food Safety Agency}

The European Food Safety Agency (EFSA) Panel on Dietetic Products, Nutrition and Allergies published in a Scientific Opinion on Dietary Reference Values 
(DRVs) for iodine produced DRVs for iodine, which were provided in terms of Adequate Intake in 2014 [22]. The updated data provided by EUthyroid should enable the revision of these DRVs, where necessary, to reflect the current iodine status in EU countries. For instance, the proposed adequate intake for lactating women of $200 \mu \mathrm{g} /$ day assumes the existence of substantial iodine stores in conditions of adequate iodine status before pregnancy. However, EUthyroid is likely to reveal the fact that many European women of childbearing age do not enter pregnancy with substantial iodine stores; this is certainly the case in the United Kingdom [23-25].

\section{European Thyroid Association Public}

\section{Health Committee}

The European Thyroid Association (ETA) has been providing policy advice relating to all aspects of thyroid disease for 50 years. During the funding period of EUthyroid, regular reports have been given to the committee. The ETA will consider the final report of EUthyroid and publicize its recommendations. It will also consider how best to advise on future policy for iodine nutrition in Europe.

\section{World Iodine Association}

World Iodine Association (WIA) is an international non-profit organization established to support and represent iodine producers, processors, formulators, distributors and end users in relevant industry and official government bodies around the world. Parallel interests between WIA and EUthyroid include the advocacy towards international institutions and key stakeholders of the optimum use of iodine in human nutrition, the transfer of scientific evidence on IDD prevention to the general public and to policymakers and to ensure the high quality of iodine production and food processing.

There is close contact between EUthyroid and the WIA. At the IGN satellite meeting of the ETA 2017 congress, which was co-organized by EUthyroid, the WIA reported on current activities and ambitions of WIA. Likewise, EUthyroid members gave presentations at the 2007 WIA congress on Iodine and Health and are members of the WIA scientific advisory board.

\section{European Salt Producer's Association}

To implement the introduction of iodised salt into European countries that do not currently consume it, European salt producer's association (EU Salt) will be of great assistance. EU Salt has extensive salt company networks that can facilitate the production and regulation of iodised salt for public consumption. Contacts between members of EUthyroid and EU Salt have been strengthened and their help is much appreciated.

\section{Iodine Global Network}

The IGN has strongly supported the EUthyroid initiative. It recognizes that while optimal iodine nutrition is being achieved in many countries in Asia, the Americas and Australasia (all hitherto iodine deficient) through the introduction of iodized salt, this in general has not occurred in Europe. It is hoped that the results of EUthyroid will encourage urgent advocacy for harmonization of iodine supply in the whole continent of Europe.

\section{Advocacy Issues: National Policy Officers}

Populations face changing environmental conditions and nutritional behavior. Promoting restricted salt consumption and the increasing use of milk-free dairy products are only 2 examples that may worsen the iodine status of populations emphasizing the need for regular monitoring studies. Since the responsibility for health issues in the EU lies with the single member states, national authorities are responsible for state-of-the-art monitoring. An EU regulation statement would support efforts to coordinate collaboration, would support evidence-based studies and establish quality control of ongoing programmes.

Advocacy is required to promote the following crucial objectives:

- To educate all partners involved in iodine-deficiency control/ monitoring to facilitate and improve their collaboration with national health authorities,

- To increase the awareness of national policymakers of the importance of monitoring iodine supply to obviate easily preventable adverse health and educational consequences,

- To mobilize national policymakers to take responsibility to raise awareness among communities of the importance of adequate iodine consumption and the necessity for IDD prevention,

- To inform national health authorities of the need to maintain their supervision of the salt and food industries with respect to iodine supply,

- To bring current changes in environmental and dietary behavior specific to each country and to the whole European population to the attention of national policymakers,

- To cooperate with consumer associations to advocate consumption of the required amount of iodine according to dietary patterns; attitudes of consumers also affect legislation efforts,

- To inform the general public by appropriate campaigns, preferably funded by public agencies, 
- To actively involve industry, including the salt and food industries, and agriculture to control and ultimately prevent iodine deficiency,

- To establish an iodine working group in each country to prepare a detailed and scheduled activity plan,

- To ensure that actions aiming to improve iodine intake in populations are implemented and that they are in line with current dietary recommendations and salt reduction initiatives. Emphasis should be placed on replacing non-iodized salt with iodized in the majority of food products.

\section{Publicity, Press and Media}

Evidence-based policymaking reflects the belief that social goals are best served when policy decisions are based on rigorous and comprehensive scientific evidence. Modern democracies are under intense influence from pressure groups that present scientific evidence in a piecemeal, manipulated, or cherry-picked manner. The term policy-based evidence making has been coined to reflect a process in which evidence is selected to conform to certain ideological positions and thus selected facts are used to support conceived wisdom. In such a scenario, selected scientific evidence is misappropriated to lend legitimacy to decisions and signal the intention of the decision makers to settle political debate [26].

The EU has set up a "Scientific Advice Mechanism," which supports decision making of the College of European Commissioners upon request with independent scientific advice. However, a path for scientific input to enter policy making in areas where no requests are formulated remains less obvious, not only on the European but also on the national level. Many theories of policymaking remain stuck in an outdated deficiency model, which presumes that when the scientific community reaches consensus on a topic, the evidence will somehow enter decision-making processes. In particular, it becomes much more obvious that participation in policy debates is not driven by a desire to be technically accurate, but rather by a need for political success [27]. It is not even clear on which remit scientists should participate in decision-making processes and what resources they would draw on to compete in the political arena with commercial and political interests. Therefore, today many scientists are confused about how to reach policy makers with their scientific evidence.

Under the specific remit to influence decisions, EUthyroid allocated a considerable amount of time and resources towards achieving improved IDD monitoring and prevention in Europe. Therefore, EUthyroid engaged

Public-Health Impact of Thyroid Research not only an interested public and the wider scientific community, but also policy makers at the national and European level.

Under the guidance of the IGN, an experienced team was established to implement a dissemination plan, which rested on the 6 pillars:

1. Producing scientific evidence on iodine monitoring and prevention programmes.

2. Generating high-quality content to engage various stakeholders.

3. Exploiting an extensive network of regional and national contacts.

EUthyroid partners have been proactively distributing facts about IDD through the project website and social media. Press releases have been published, national stakeholders contacted and meetings attended. The EUthyroid twitter account has reached more than 180 followers. While this number is modest and are far from reaching any significant proportion of the general audience, it compares well to other dissemination activities of research projects, which are frequently in the low 2-digit numbers. To all partners of EUthyroid, the fact that the public remains oblivious to the problem of iodine deficiency remains a great challenge. If a general audience, supported by media attention, recognizes a public-health concern as a pressing need, policymakers are more likely to be engaged and more likely to recommend urgent action.

\section{Conclusions}

EUthyroid has made steps forward to achieve an optimally iodine sufficient Europe. Our challenge is to inspire a greater sense of urgency in both policymakers and the wider public to address this remediable deficit that is increasing the burden of IDD to societies and individuals and adversely affecting the mental abilities of our children.

\section{Acknowledgment}

EUthyroid has received funding from the European Union's Horizon 2020 research and innovation program under grant agreement number 634453.

\section{Disclosure Statement}

The authors declare that there are no conflicts of interest to disclose. 


\section{References}

1 http://www.who.int/vmnis/iodine/status/en/ (last access December 21, 2017).

2 Laurberg P, Pedersen KM, Hreidarsson A, Sigfusson N, Iversen E, Knudsen PR: Iodine intake and the pattern of thyroid disorders: a comparative epidemiological study of thyroid abnormalities in the elderly in Iceland and in Jutland, Denmark. J Clin Endocrinol Metab 1998;83:765-769.

3 Völzke H, Lüdemann J, Robinson DM, Spieker KW, Schwahn C, Kramer A, John U, Meng $\mathrm{W}$ : The prevalence of undiagnosed thyroid disorders in a previously iodine-deficient area. Thyroid 2003;13:803-810.

4 Collet TH, Gussekloo J, Bauer DC, den Elzen WP, Cappola AR, Balmer P, Iervasi G, Åsvold BO, Sgarbi JA, Völzke H, Gencer B, Maciel RM, Molinaro S, Bremner A, Luben RN, Maisonneuve P, Cornuz J, Newman AB, Khaw KT, Westendorp RG, Franklyn JA, Vittinghoff E, Walsh JP, Rodondi N; Thyroid Studies Collaboration: Subclinical hyperthyroidism and the risk of coronary heart disease and mortality. Arch Intern Med 2012;172:799809.

5 Zimmermann MB: Research on iodine deficiency and goiter in the 19th and early 20th centuries. J Nutr 2008;138:2060-2063.

6 The EUthyroid Consortium: The Krakow Declaration on Iodine: Tasks and responsibilities for prevention programs targeting iodine deficiency disorders. Eur Thyroid J 2018;7:201-204.

7 Völzke H, Caron P, Dahl L, de Castro JJ, Erlund I, Gaberšček S, Gunnarsdottir I, Hubalewska-Dydejczyk A, Ittermann T, Ivanova L, Karanfilski B, Khattak RM, Kusić Z, Laurberg P, Lazarus JH, Markou KB, MorenoReyes R, Nagy EV, Peeters RP, Pīrāgs V, Podoba J, Rayman MP, Rochau U, Siebert U, Smyth PP, Thuesen BH, Troen A, Vila L, Vitti P, Zamrazil V, Zimmermann MB: Ensuring effective prevention of iodine deficiency disorders. Thyroid 2016;26:189-196.

8 Ittermann T, Johner S, Below H, Leiterer M, Thamm M, Remer T, Völzke H: Interlaboratory variability of urinary iodine measurements. Clin Chem Lab Med 2018;56:441-447.

9 Zimmermann MB, Andersson M: Assessment of iodine nutrition in populations: past, present, and future. Nutr Rev 2012;70:553570 .

10 Zimmermann MB, de Benoist B, Corigliano S, Jooste PL, Molinari L, Moosa K, Pretell EA, AlDallal ZS, Wei Y, Zu-Pei C, Torresani T: Assessment of iodine status using dried blood spot thyroglobulin: development of reference material and establishment of an international reference range in iodine-sufficient children. J Clin Endocrinol Metab 2006;91:4881-4887.

11 Karmisholt J, Laurberg P, Andersen S: Recommended number of participants in iodine nutrition studies is similar before and after an iodine fortification programme. Eur J Nutr 2014;53:487-492.

12 Golding J; ALSPAC Study Team: The Avon Longitudinal Study of Parents and Children (ALSPAC) - study design and collaborative opportunities. Eur J Endocrinol 2004; 151(suppl 3):U119-U123.

13 Valera-Gran D, Navarrete-Muñoz EM, Garcia de la Hera M, Fernández-Somoano A, Tardón A, Ibarluzea J, Balluerka N, Murcia M, González-Safont L, Romaguera D, Julvez J, Vioque J; INMA Project: Effect of maternal high dosages of folic acid supplements on neurocognitive development in children at 4-5 y of age: the prospective birth cohort Infancia y Medio Ambiente (INMA) study. Am J Clin Nutr 2017;106:878-887.

14 Kooijman MN, Kruithof CJ, van Duijn CM, Duijts L, Franco OH, van IJzendoorn $\mathrm{MH}$, de Jongste JC, Klaver CC, van der Lugt A, Mackenbach JP, Moll HA, Peeters RP, Raat H, Rings EH, Rivadeneira F, van der Schroeff MP, Steegers EA, Tiemeier H, Uitterlinden AG, Verhulst FC, Wolvius E, Felix JF, Jaddoe VW: The Generation R Study: design and cohort update 2017. Eur J Epidemiol 2016;31:1243-1264.

15 Rochau U, Sroczynski G, Wolf D, Schmidt S, Jahn B, Kluibenschaedl M, Conrads-Frank A, Stenehjem D, Brixner D, Radich J, Gastl G, Siebert U: Cost-effectiveness of the sequential application of tyrosine kinase inhibitors for the treatment of chronic myeloid leukemia. Leuk Lymphoma 2015;56:2315-2325.

16 Dunn JT: Complacency: the most dangerous enemy in the war against iodine deficiency. Thyroid 2000;10:681-683.
17 Zimmermann MB: The effects of iodine deficiency in pregnancy and infancy. Paediatr Perinat Epidemiol 2012;26(suppl 1):108-117.

18 O'Kane SM, Pourshahidi LK, Mulhern MS, Weir RR, Hill S, O’Reilly J, Kmiotek D, Deitrich C, Mackle EM, Fitzgerald E, Lowis C, Johnston M, Strain JJ, Yeates AJ: The effect of processing and seasonality on the iodine and selenium concentration of cow's milk produced in Northern Ireland (NI): implications for population dietary intake. Nutrients 2018; 10:pii:E287

19 Andersen S, Noahsen P, Westergaard L, Laurberg P: Reliability of thyroglobulin in serum compared with urinary iodine when assessing individual and population iodine nutrition status. Br J Nutr 2017;117:441-449.

20 Marangoni F, Cetin I, Verduci E, Canzone G, Giovannini M, Scollo P, Corsello G, Poli A: maternal diet and nutrient requirements in pregnancy and breastfeeding. An Italian consensus document. Nutrients 2016;8:pii:E629.

21 Møllehave LT, Linneberg A, Skaaby T, Knudsen N, Ehlers L, Jørgensen T, Thuesen BH: Trends in Costs of Thyroid Disease Treatment in Denmark during 1995-2015. Eur Thyroid J 2018;7:75-83.

22 European Food Safety Authority (EFSA): Scientific opinion on dietary reference values for iodine. EFSA J 2014; 12:3660.

23 Bath SC, Sleeth ML, McKenna M, Walter A, Taylor A, Rayman MP: Iodine intake and status of UK women of childbearing age recruited at the University of Surrey in the winter. $\mathrm{Br}$ J Nutr 2014;112:1715-1723.

24 Vanderpump MP, Lazarus JH, Smyth PP, Laurberg P, Holder RL, Boelaert K, Franklyn JA; British Thyroid Association UK Iodine Survey Group: Iodine status of UK schoolgirls: a cross-sectional survey. Lancet 2011; 377:2007-2012.

25 Lampropoulou M, Lean M, Combet Aspray E: Iodine status of women of childbearing age in Scotland. Proc Nutr Soc 2012;71:E143.

26 http://sloanreview.mit.edu/article/is-decision-based-evidence-making-necessarilybad/(last access December 27, 2017).

27 http://www.tandfebooks.com/action/showB ook? doi=10.4324/9781315675008 (last access December 12, 2017). 